Uncertainty Shocks in a Model of Effective Demand: Comment

Oliver de Groot, Alexander W. Richter and Nathaniel A. Throckmorton

Federal Reserve Bank of Dallas

Research Department

Working Paper 1706 


\title{
Uncertainty Shocks in a Model of Effective Demand: Comment*
}

\author{
Oliver de Groot \\ Alexander W. Richter \\ Nathaniel A. Throckmorton \\ May 19, 2017
}

\begin{abstract}
Basu and Bundick (2017) show a second moment intertemporal preference shock creates meaningful declines in output in a sticky price model with Epstein and Zin (1991) preferences. The result, however, rests on the way they model the shock. If a preference shock is included in Epstein-Zin preferences, the distributional weights on current and future utility must sum to 1 , otherwise it creates an asymptote in the response to the shock with unit intertemporal elasticity of substitution. When we change the preferences so the weights sum to 1 , the asymptote disappears as well as their main results-uncertainty shocks generate small increases in output and comovement with consumption and investment that is at odds with the data. We examine three changes to the model-recalibration, a risk-premium shock, and a disaster risk-type shock-to try and restore their results, but in all three cases the model is unable to match VAR evidence.
\end{abstract}

Keywords: Stochastic Volatility, Epstein-Zin Preferences, Uncertainty, Economic Activity JEL Classifications: D81, E32

\footnotetext{
*de Groot, School of Economics and Finance, University of St Andrews, St Andrews, Fife, KY16 9AL, United Kingdom (ovdg@st-andrews.ac.uk); Richter, Research Department, Federal Reserve Bank of Dallas, and Auburn University, 2200 N. Pearl Street, Dallas, TX 75201 (alex.richter@ dal.frb.org); Throckmorton, Department of Economics, College of William \& Mary, P.O. Box 8795, Williamsburg, VA 23187 (nathrockmorton@wm.edu). We thank Jim Dolmas, Paola Manzini, Ron Mau, Mike Plante, Kemal Ozbek, Alan Sutherland, Todd Walker, and Fabrizio Zilliboti for comments and discussions that improved the paper. The views expressed in this paper are those of the authors and do not necessarily reflect the views of the Federal Reserve Bank of Dallas or the Federal Reserve System.
} 


\section{INTRODUCTION}

Basu and Bundick (2017)—BB, hereafter-find demand uncertainty can explain a substantial fraction of the fall in output, consumption, and investment that occurred in late 2008. To establish their results, BB build a small-scale dynamic stochastic general equilibrium model with monopolistic competition and sticky prices. Demand uncertainty is modeled as a stochastic volatility (SV) shock to a representative household's intertemporal preferences and is calibrated by matching impulse responses to a one standard deviation increase in the VXO from a vector autoregression (VAR). Their work complements a large literature on the role of SV ("uncertainty") shocks that emerged in the last decade (e.g., Bachmann et al. (2013); Bloom (2009); Born and Pfeifer (2014); FernándezVillaverde et al. (2015a,b, 2011); Justiniano and Primiceri (2008); Mumtaz and Zanetti (2013)).

We show BB's results depend on their specification of recursive, Epstein and Zin (1991), preferences and their choice for the intertemporal elasticity of substitution (IES). If a preference shock is included in Epstein-Zin preferences, the distributional weights on current and future utility must sum to 1 , otherwise it creates an asymptote in the response to the shock with unit IES. In the BB model, the IES equals 0.95 and the shock only hits current utility, so the sum of the weights differs from 1 . They show a one standard deviation preference volatility shock (demand uncertainty) causes output to decline by $0.13 \%$ on impact, which is much larger than the literature finds. For example, Justiniano and Primiceri (2008) estimate a similar model with several sources of stochastic volatility and find preference volatility shocks do not have a meaningful effect on output. Richter and Throckmorton (2017) estimate a model where time-varying uncertainty arises from stochastic volatility as well as the state of the economy. They find the same shock affects output by less than $0.01 \%$. The BB model can generate an arbitrarily large decline in output by setting the IES even closer to 1 . If the IES is above 1 output increases, and if it is less than 0.5 there is almost no effect.

Despite the importance of the IES in economic models, there is little consensus in the literature about its value. Hall (1988) argues the empirical evidence supports an IES close to zero. Basu and Kimball (2002) find an IES of about 0.5 and Smets and Wouters (2007) estimate a value of roughly 0.7 . In much of the literature, it is common to work with log-preferences (i.e., an IES of 1). In contrast, Bansal and Yaron (2004) choose an IES of 1.5. They argue earlier empirical work ignored the effect of time-varying volatility, creating downward bias in the estimates of the IES. Similarly, van Binsbergen et al. (2012) estimate a model with Epstein-Zin preferences and find an IES of 1.73. Considering the range of values in the literature, the preferences in BB can generate almost any size and sign impact responses of output and investment to a demand uncertainty shock.

We show the asymptote disappears with preferences where the weights on current and future utility sum to 1 . Unlike the BB setup, the aggregator over current and future utility in our preferences becomes Cobb-Douglas as the IES approaches 1 just like in Epstein and Zin (1991), and the model's predictions are robust to small changes in the IES. However, there are two problems for BB's conclusions. One, positive demand uncertainty shocks have small effects on economic activity. Two, output and investment increase and they no longer positively comove with consumption.

We examine three changes to the model to assess whether we are able to recover BB's results. One, we rerun their impulse response matching exercise, but the algorithm cannot find parameters for the uncertainty process that allow the model to match the responses from the VAR. We also consider different values for the structural parameters. Higher capital adjustment costs, risk-aversion, or price-adjustment costs attenuate the increases in output and investment. However, those parameters do not fix the comovement problem unless they are much larger than the values in the 
literature, and the effect on output is much smaller than in BB. Two, we model demand uncertainty with a Smets and Wouters (2007) risk-premium shock instead of the preference shock. The new demand uncertainty shock fixes the comovement problem but creates a tradeoff between matching the VAR responses of output and stock market volatility. Three, we modify the BB preferences to exploit the observational equivalence between disaster risk shocks and preference shocks following Gourio (2012). With this shock, the asymptote appears when the IES equals 0 while the effect on output is zero when the IES is unity and there is a tradeoff similar to the risk premium shock.

The paper proceeds as follows. Section 2 describes the BB preferences and our specification. Section 3 compares the two specifications with impulse responses to first and second moment preference shocks. Section 4 analytically solves an endowment economy with both preference specifications. Section 5 considers three potential changes to the BB model. Section 6 concludes.

\section{PREFERENCE SPECIFICATION}

Following Epstein and Zin (1991), BB adopt a recursive structure for intertemporal utility, where a representative household chooses sequences of consumption, $c_{t}$, and labor, $n_{t}$, to maximize

$$
U_{t}^{B B}=\left[a_{t}(1-\beta) u\left(c_{t}, n_{t}\right)^{(1-\sigma) / \theta}+\beta\left(E_{t}\left[\left(U_{t+1}^{B B}\right)^{1-\sigma}\right]\right)^{1 / \theta}\right]^{\theta /(1-\sigma)}, \quad 1 \neq \psi>0,
$$

where $\theta \equiv(1-\sigma) /(1-1 / \psi), \sigma \geq 0$ determines the coefficient of relative risk aversion, $\psi \geq 0$ is the intertemporal elasticity of substitution, $\beta \in(0,1)$ is the subjective discount factor, and $E_{t}$ is the mathematical expectation operator conditional on information in period $t$. The current period consumption-leisure basket is defined as $u\left(c_{t}, n_{t}\right)=c_{t}^{\eta}\left(1-n_{t}\right)^{1-\eta}$, where $\eta$ determines the Frisch elasticity of labor supply. The coefficient on current utility, $a_{t}$, is a preference shock that follows

$$
\begin{gathered}
a_{t}=\left(1-\rho_{a}\right) a+\rho_{a} a_{t-1}+\sigma_{t-1}^{a} \varepsilon_{t}^{a}, 0 \leq \rho_{a}<1, \varepsilon_{t}^{a} \sim \mathbb{N}(0,1), \\
\sigma_{t}^{a}=\left(1-\rho_{\sigma^{a}}\right) \sigma^{a}+\rho_{\sigma^{a}} \sigma_{t-1}^{a}+\sigma^{\sigma^{a}} \varepsilon_{t}^{\sigma^{a}}, 0 \leq \rho_{\sigma^{a}}<1, \varepsilon_{t}^{\sigma^{a}} \sim \mathbb{N}(0,1),
\end{gathered}
$$

where the standard deviation of the preference shock, $\sigma_{t}^{a}$, follows an independent Normal process (meaning $\sigma_{t}^{a}$ and $\varepsilon_{t}^{a}$ are uncorrelated) to introduce time-varying demand uncertainty into the model.

Given (1), the stochastic discount factor (SDF) that prices any 1-period asset is given by

$$
m_{t, t+1}^{B B}=\beta\left(\frac{a_{t+1}}{a_{t}}\right)\left(\frac{u\left(c_{t+1}, n_{t+1}\right)}{u\left(c_{t}, n_{t}\right)}\right)^{\frac{1-\sigma}{\theta}}\left(\frac{c_{t}}{c_{t+1}}\right)\left(\frac{\left(V_{t+1}^{B B}\right)^{1-\sigma}}{E_{t}\left[\left(V_{t+1}^{B B}\right)^{1-\sigma}\right]}\right)^{1-\frac{1}{\theta}},
$$

where $V_{t}^{B B}$ is the value function that solves the household's constrained optimization problem.

The utility function in (1) is constructed from two components. One, a time aggregator that characterizes preferences over the current consumption-leisure basket and the certainty equivalent of future utility. Two, a risk aggregator that characterizes preferences for risk over future utility. We focus on the specification of the time aggregator. When $a_{t}=1$, the time aggregator is a CES function with distributional weights $1-\beta$ and $\beta$, respectively. The CES function then has the desirable property that for a unit IES, the time aggregator becomes Cobb-Douglas and (1) becomes

$$
U_{t}^{B B}=u\left(c_{t}, n_{t}\right)^{(1-\beta)}\left(E_{t}\left[\left(U_{t+1}^{B B}\right)^{1-\sigma}\right]\right)^{\beta /(1-\sigma)}, \quad \psi=1 .
$$

However, if $a_{t} \neq 1$, the distributional weights, $a_{t}(1-\beta)$ and $\beta$, do not sum to one and the recursive utility function in (1) has the following undesirable limiting properties as the IES tends to 1 :

$$
\lim _{\psi \rightarrow 1^{-}} U_{t}^{B B}=0(\infty) \text { for } a_{t}>1(<1), \quad \lim _{\psi \rightarrow 1^{+}} U_{t}^{B B}=\infty(0) \text { for } a_{t}>1(<1) .
$$


The asymptote that occurs with unit IES is crucial for BB's results. To eliminate the undesirable asymptote, we propose a natural alternative to (1), where the distributional weights on current and future utility sum to 1 for all $a_{t} \in(0,1 / \beta)$. The alternative preference specification is given by

$$
U_{t}^{A L T}= \begin{cases}{\left[\left(1-a_{t} \beta\right) u\left(c_{t}, n_{t}\right)^{(1-\sigma) / \theta}+a_{t} \beta\left(E_{t}\left[\left(U_{t+1}^{A L T}\right)^{1-\sigma}\right]\right)^{1 / \theta}\right]^{\theta /(1-\sigma)}} & \text { for } 1 \neq \psi>0 \\ u\left(c_{t}, n_{t}\right)^{\left(1-a_{t} \beta\right)}\left(E_{t}\left[\left(U_{t+1}^{A L T}\right)^{1-\sigma}\right]\right)^{a_{t} \beta /(1-\sigma)} & \text { for } \psi=1\end{cases}
$$

and the SDF becomes

$$
m_{t, t+1}^{A L T}=a_{t} \beta\left(\frac{1-a_{t+1} \beta}{1-a_{t} \beta}\right)\left(\frac{u\left(c_{t+1}, n_{t+1}\right)}{u\left(c_{t}, n_{t}\right)}\right)^{\frac{1-\sigma}{\theta}}\left(\frac{c_{t}}{c_{t+1}}\right)\left(\frac{\left(V_{t+1}^{A L T}\right)^{1-\sigma}}{E_{t}\left[\left(V_{t+1}^{A L T}\right)^{1-\sigma}\right]}\right)^{1-\frac{1}{\theta}} .
$$

Our preferences become Cobb-Douglas as the IES tends to 1 and are therefore continuous in $\psi$.

To calibrate the new shock, we use expected utility preferences $(\sigma=1 / \psi)$ since in this case the value function does not appear in the SDF. The log-linear SDF in each model is then given by

$$
\begin{gathered}
\hat{m}_{t, t+1}^{B B}=\hat{a}_{t+1}-\hat{a}_{t}+(1-\sigma)\left(\hat{u}_{t+1}-\hat{u}_{t}\right)+\hat{c}_{t}-\hat{c}_{t+1}, \\
\hat{m}_{t, t+1}^{A L T}=-\left(\beta \hat{a}_{t+1}-\hat{a}_{t}\right) /(1-\beta)+(1-\sigma)\left(\hat{u}_{t+1}-\hat{u}_{t}\right)+\hat{c}_{t}-\hat{c}_{t+1} .
\end{gathered}
$$

When $\beta$ is close to 1 we can generate near-identical impulse responses to first moment preference shocks by scaling the shock standard deviations, $\sigma^{a}$ and $\sigma^{\sigma^{a}}$, by $1-\beta$ and flipping the sign of the shock. Appendix A shows the similarity in the responses across the two preference specifications.

\section{IMPACT OF PREFERENCE SHOCKS}

Figure 1 plots the impact effect on output, consumption, and investment from a one standard deviation shock to the level, $\varepsilon_{t}^{a}$, and volatility, $\varepsilon_{t}^{\sigma^{a}}$, of $a_{t}$ as a function of the IES. The top panel shows the impact effects with BB preferences (figure 1a) and the bottom panel shows the effects with our alternative preferences (figure $1 b$ ). The circle markers show the impact effect when the IES equals 0.95- the value used by BB. Aside from the preferences, the model is identical to BB.

The impact effects of the level shock with BB preferences show an asymptote appears in the responses of all three variables when the IES equals 1 , but it only has a meaningful effect on the responses if the IES is between 0.95 and 1.05. In response to a volatility shock, the asymptote also appears when the IES equals 1 , but it affects the responses for a wider range of IES values. ${ }^{1}$ For example, there is almost no effect on output when the IES is less than 0.5 , whereas output decreases by about $0.015 \%(0.025 \%, 0.06 \%, 0.13 \%)$ when it equals $0.7(0.8,0.9,0.95)$. By setting the IES equal to 0.99 , the model is able to generate an enormous $0.68 \%$ decline in output on impact. When the IES is alternatively set to 1.05 , output instead rises on impact by $0.13 \%$. In short, small changes in the IES lead to very different conclusions, so it is possible to produce any effect of uncertainty.

The asymptote never appears with our alternative preferences. ${ }^{2}$ As a result, small changes in the value of the IES no longer significantly alter the responses to demand uncertainty shocks, even

\footnotetext{
${ }^{1}$ Appendix B shows an asymptote also appears in response to an increase in the level and volatility of technology.

${ }^{2}$ Rudebusch and Swanson (2012) rewrite Epstein and Zin's preference specification as $U_{t}^{R S}=(1-\beta) v\left(c_{t}, n_{t}\right)+$ $\beta\left(E_{t}\left[\left(U_{t+1}^{R S}\right)^{1-\alpha}\right]\right)^{1 /(1-\alpha)}$. That formulation is particularly useful when using utility kernels, $v_{t}$, that are additively separable in $c_{t}$ and $n_{t}$. RS and BB preferences are equivalent when $v\left(c_{t}, n_{t}\right) \equiv u\left(c_{t}, n_{t}\right)^{(1-\sigma) / \theta}, \alpha \equiv 1-\theta$, and $U_{t}^{R S} \equiv\left(U_{t}^{B B}\right)^{(1-\sigma) / \theta}$. Therefore, the RS reformulation does not eliminate the asymptote that occurs with unit IES.
} 

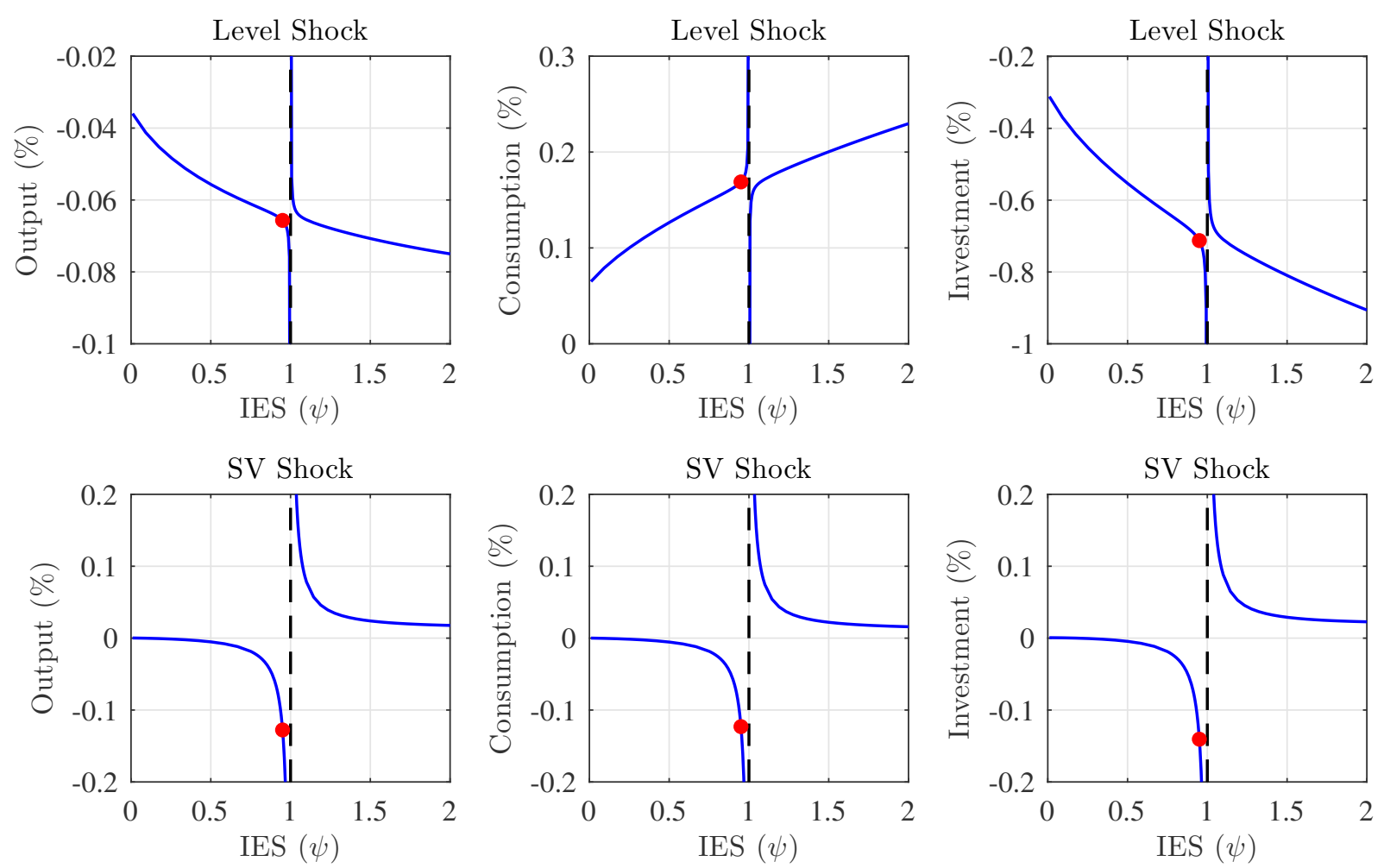

(a) Impact responses with BB preferences.
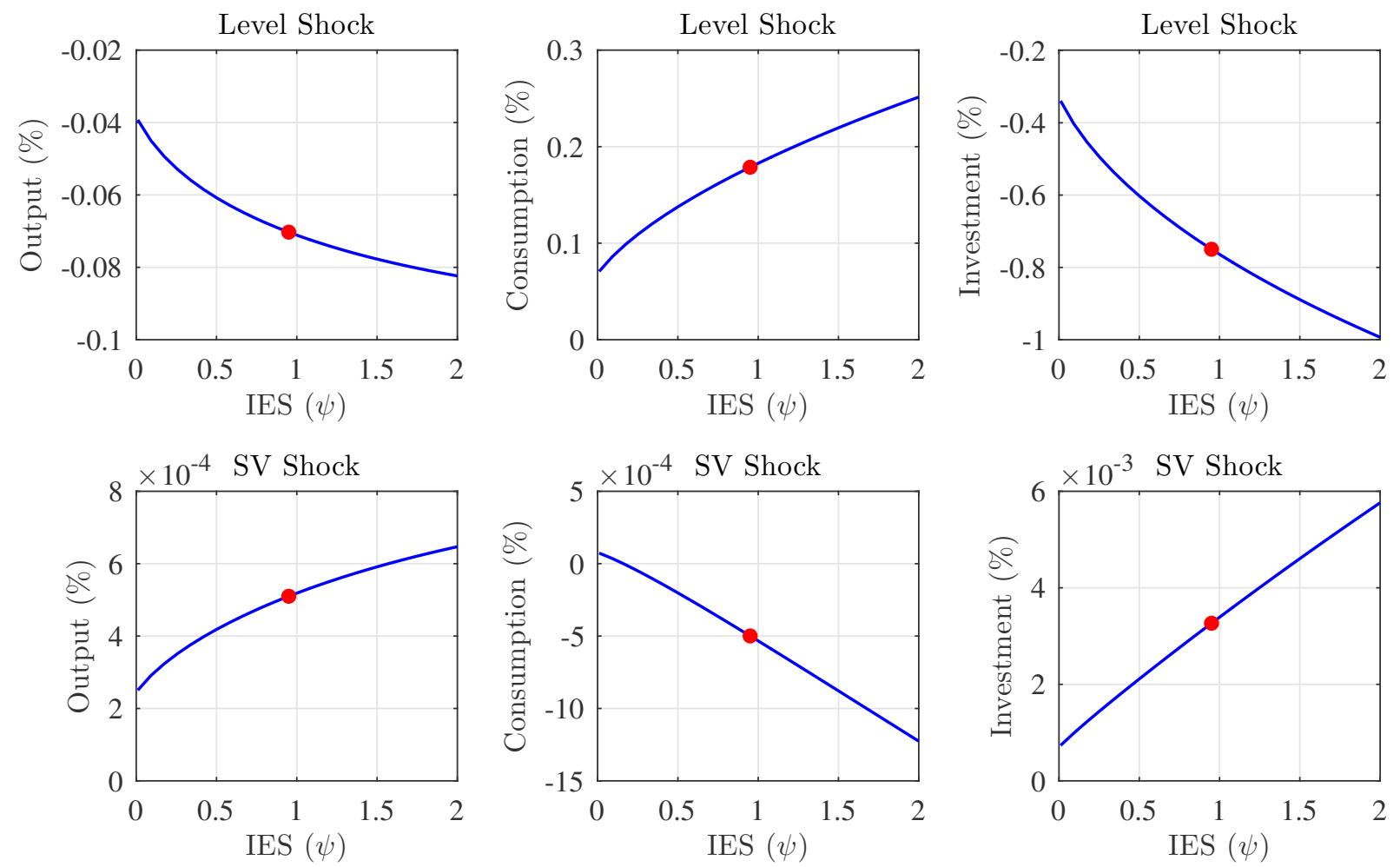

(b) Impact responses with our alternative preferences.

Figure 1: Impact effect on output, consumption, and investment from a 1 standard deviation level and volatility shock to household preferences. The circle markers show the impact effect when the IES equals 0.95 , the value used by BB. 
though the responses to a level shock are very similar across the two preference specifications. Unfortunately, our preferences create two problems for BB's conclusions. One, the economic effect of a demand uncertainty shock is no longer economically significant. Consumption falls, for example, by $0.0005 \%$ on impact in response to a one standard deviation increase in uncertainty. Two, higher uncertainty increases output and investment and causes consumption to fall. The comovement problem arises because higher demand uncertainty generates both an increase in precautionary savings (reducing consumption) and a rise in precautionary labor supply (increasing output). BB argue sticky prices and monopolistic competition are sufficient to produce a decrease in labor supply. Our results show that correcting the preference specification overturns that result.

\section{ANALYTICAL EXAMPLE}

This section builds a simple model that allows us to obtain an analytical solution, which shows the asymptote in the BB model is due to their preference specification and not some other feature. We show the asymptote disappears with our alternative specification. BB use third-order perturbation methods to solve their model, but we follow the finance literature and construct a Campbell-Shiller log-linear approximation that exploits the assumption of log-normal shocks. The model is similar to a small-open endowment economy model. Appendix C solves an even simpler 2-period model.

4.1 MODEL A representative household chooses sequences of consumption, $c_{t}$, to maximize

$$
U_{t}=\left[a_{t}(1-\beta)\left(c_{t} / c\right)^{1-\chi}+\beta\left(Z_{t} / Z\right)^{1-\chi}\right]^{1 /(1-\chi)}
$$

where $\chi=1 / \psi$ is the inverse IES and the risk aggregator, $Z_{t}$, is defined as $Z_{t} \equiv\left(E_{t}\left[U_{t+1}^{1-\sigma}\right]\right)^{1 /(1-\sigma)}$. The preferences are normalized so $U=1$ in steady state. For simplicity, we assume $a_{t}$ follows

$$
\begin{gathered}
\hat{a}_{t} \equiv \log a_{t}-\log a=\sigma_{a, t-1} \varepsilon_{t}, \quad \varepsilon_{t} \sim \mathbb{N}(0,1), \\
\hat{\sigma}_{a, t}^{2} \equiv \sigma_{a, t}^{2}-\sigma_{a}^{2}=\sigma_{\sigma^{a}} \varepsilon_{\sigma, t}, \quad \varepsilon_{\sigma, t} \sim \mathbb{N}(0,1),
\end{gathered}
$$

where a hat denotes log-deviations from the steady state. The household's choices are constrained by $c_{t}+w_{t+1} / r=w_{t}$, where $w_{t}$ is wealth and $r$ is the gross return. The Euler equation is given by

$$
1=E_{t}\left[\beta r\left(\frac{a_{t+1}}{a_{t}}\right)\left(\frac{c_{t+1}}{c_{t}}\right)^{-\chi}\left(\frac{V_{t+1}}{Z_{t}}\right)^{\chi-\sigma}\left(\frac{1}{Z}\right)^{1-\chi}\right],
$$

where $V_{t}$ is the value function that solves the household's constrained optimization problem.

4.2 LOG-LINEAR SOLUTION We posit the following minimum state variable solution:

$$
\begin{aligned}
\hat{c}_{t} & =A_{w} \hat{w}_{t}+A_{a} \hat{a}_{t}+A_{\sigma} \hat{\sigma}_{a, t}^{2}, \\
\hat{V}_{t} & =B_{w} \hat{w}_{t}+B_{a} \hat{a}_{t}+B_{\sigma} \hat{\sigma}_{a, t}^{2}, \\
\hat{w}_{t+1} & =C_{w} \hat{w}_{t}+C_{a} \hat{a}_{t}+C_{\sigma} \hat{\sigma}_{a, t}^{2} .
\end{aligned}
$$

$A_{\sigma}$ is the main object of interest, since we are concerned with the response of consumption to a demand uncertainty shock. To solve the model, we first log-linearize the value function to obtain

$$
\begin{gathered}
\hat{V}_{t}=(1-\beta)\left[\hat{a}_{t} /(1-\chi)+\hat{c}_{t}\right]+\beta \hat{Z}_{t}, \\
\hat{Z}_{t}=-\log Z+\log \left(E_{t}\left[\exp \left((1-\sigma) \hat{V}_{t+1}\right)\right]\right) /(1-\sigma) .
\end{gathered}
$$

Notice that in log-linearized form, $\hat{a}_{t}$ enters the value function equation with coefficient $1 /(1-\chi)$. It is the presence of this term that will generate the asymptote in $A_{\sigma}$ when the IES is equal to 1. 
After substituting the guess into the value function and then equating coefficients, we find

$$
\begin{gathered}
B_{w}=(1-\beta) A_{w}+\beta B_{w} C_{w}, \quad B_{a}=(1-\beta) /(1-\chi)+(1-\beta) A_{a}+\beta B_{w} C_{a}, \\
B_{\sigma}=(1-\beta) A_{\sigma}+\beta\left(B_{w} C_{\sigma}+(1-\sigma) B_{a}^{2} / 2\right) .
\end{gathered}
$$

Next, we log-linearize the Euler equation to obtain

$$
0=\log (\beta R)-(1-\sigma) \log Z+\log \left(E_{t}\left[\exp \left(\hat{a}_{t+1}-\hat{a}_{t}-\chi\left(\hat{c}_{t+1}-\hat{c}_{t}\right)+(\chi-\sigma)\left(\hat{V}_{t+1}-\hat{Z}_{t}\right)\right)\right]\right) .
$$

As before, we substitute in the unknown decision rules, collect terms, and take expectations. Since the Euler equation must hold at all points in the state space, we obtain the following restrictions:

$$
\begin{gathered}
0=A_{w}\left(1-C_{w}\right) \chi, \quad 0=\left(1-A_{a} \chi\right)+A_{w} C_{a} \chi \\
0=\chi\left(A_{\sigma}-A_{w} C_{\sigma}\right)+\left(1-A_{a} \chi+(\chi-\sigma) B_{a}\right)^{2} / 2-(1-\sigma)(\chi-\sigma) B_{a}^{2} / 2 .
\end{gathered}
$$

In steady state, $c / w=\tilde{r} / r$ where $\tilde{r}=r-1$, so the log-linear budget constraint is given by $\hat{w}_{t+1}=r \hat{w}_{t}-\tilde{r} \hat{c}_{t}$. Substituting in the guess for the final time and equating coefficients yields

$$
C_{w}=r-\tilde{r} A_{w}, \quad C_{a}=-\tilde{r} A_{a}, \quad C_{\sigma}=-\tilde{r} A_{\sigma} .
$$

Thus, we have 9 equations and 9 unknown coefficients. The system implies $A_{w}=B_{w}=C_{w}=1$,

$$
\begin{gathered}
A_{a}=1 /(\chi r), \quad C_{a}=-\tilde{r} /(\chi r), \quad B_{a}=(1-\beta) /(1-\chi)+(1-\beta r) /(\chi r), \\
A_{\sigma}=-\left(\left(1-A_{a} \chi+(\chi-\sigma) B_{a}\right)^{2}-(1-\sigma)(\chi-\sigma) B_{a}^{2}\right) /(2 \chi r) .
\end{gathered}
$$

Notice $A_{\sigma}$ is a function of $B_{a}^{2}$. Since $B_{a}$ contains an asymptote when the IES equals 1 , so does $A_{\sigma}$. As $\sigma$ increases, the asymptote has a greater influence on the response of consumption to a volatility shock. Also, as $\chi$ increases (i.e., the IES decreases), the consumption response approaches 0 . In the special case when $\chi=\sigma, B_{a}$ drops out of the equation for $A_{\sigma}$, so the asymptote disappears.

4.3 Alternative Preferences We repeat the same exercise with the alternative preferences,

$$
U_{t}=\left[\left(1-a_{t} \beta\right)\left(c_{t} / c\right)^{1-\chi}+a_{t} \beta\left(Z_{t} / Z\right)^{1-\chi}\right]^{1 /(1-\chi)},
$$

so the weights on current and future utility sum to 1 . The log-linear value function is given by

$$
\hat{V}_{t}=(1-\beta) \hat{c}_{t}+\beta \hat{Z}_{t} \text {. }
$$

Notice the $\hat{a}_{t}$ term that appeared with the BB preferences drops out. The Euler equation becomes

$$
1=E_{t}\left[a_{t} \beta r\left(\frac{1-a_{t+1} \beta}{1-a_{t} \beta}\right)\left(\frac{c_{t+1}}{c_{t}}\right)^{-\chi}\left(\frac{V_{t+1}}{Z_{t}}\right)^{\chi-\sigma}\left(\frac{1}{Z}\right)^{1-\chi}\right] .
$$

Once again, we log-linearize the value function and the Euler equation, plug in the decision rules, and equate coefficients. After solving the system of equations, the new coefficients are given by

$$
\begin{gathered}
A_{a}=-1 /(\chi r(1-\beta)), \quad B_{a}=-(1-\beta r) /(\chi r(1-\beta)), \\
A_{\sigma}=-\left(\left(-\beta /(1-\beta)-A_{a} \chi+(\chi-\sigma) B_{a}\right)^{2}-(1-\sigma)(\chi-\sigma) B_{a}^{2}\right) /(2 \chi r) .
\end{gathered}
$$

Importantly, the asymptote in $A_{\sigma}$ disappears, since there is no longer an asymptote in $B_{a}$.

The gross return, $r$, is endogenous and must satisfy the steady-state Euler equation given by

$$
\begin{aligned}
0=\log (\beta r) & -\left[(1-\sigma)^{2} B_{a}^{2}-\left(-\beta /(1-\beta)-\chi A_{a}+(\chi-\sigma) B_{a}\right)^{2}\right] \sigma_{a}^{2} / 2 \\
- & {\left[(1-\sigma)^{2} B_{\sigma}^{2}-\left((\chi-\sigma) B_{\sigma}-\chi A_{\sigma}\right)^{2}\right] \omega^{2} / 2 }
\end{aligned}
$$

After substituting $r$ into (28), we find $A_{\sigma}=0$. To see that result, we guess and verify that $r=1 / \beta$ by noting that $\chi A_{a}=-\beta /(1-\beta)$ and $B_{a}=0$. Therefore, households are certainty equivalent. 

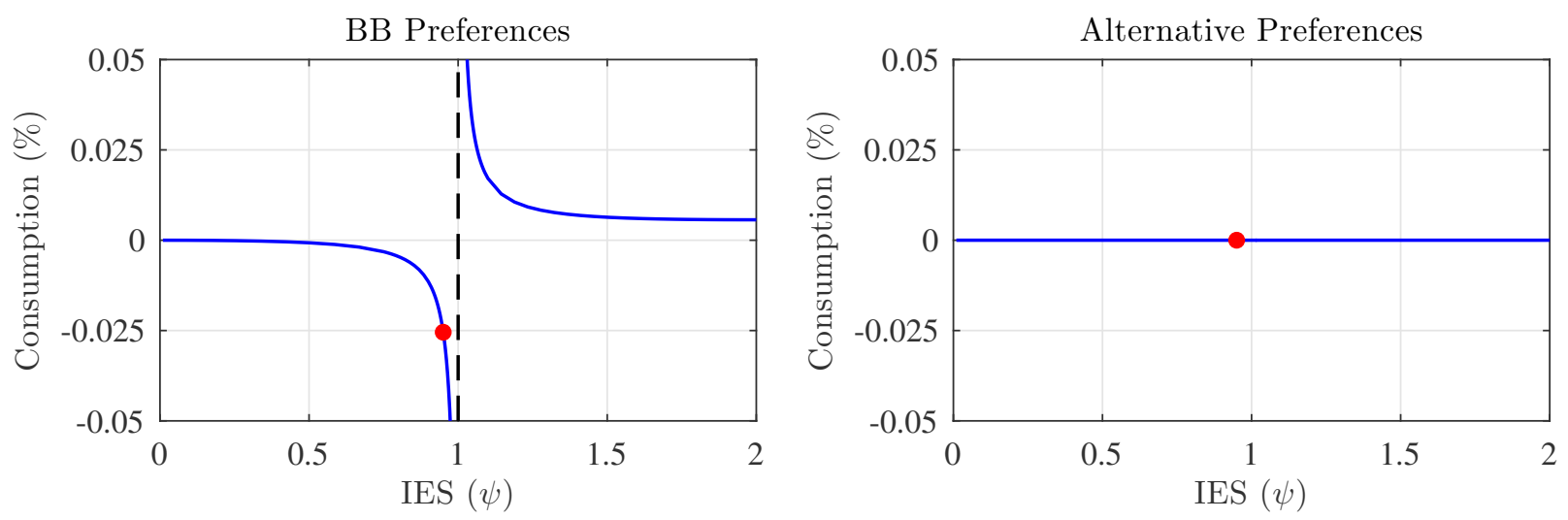

Figure 2: Impact response of consumption to a change in the standard deviation of the preference shock $\left(A_{\sigma}\right)$.

4.4 ASYMPTOTE Figure 2 plots the response of consumption to a preference volatility shock $\left(A_{\sigma}\right)$ with the $\mathrm{BB}$ preferences and our alternative specification across a range of IES values. We set the coefficient of relative risk aversion, $\sigma$, to 80 and the shock standard deviations, $\sigma_{a}$ and $\sigma_{\sigma^{a}}$, to 0.003 to match the values $\mathrm{BB}$ use. As our analytical example shows, there is no response of consumption to an increase in volatility with our alternative preferences. In contrast, the BB preferences break certainty equivalence because there is an asymptote in the response of consumption when the IES equals 1 . Hence, values of the IES between 0.75 and 1.25 have a meaningful effect on the size of the impact effect from changes in $\hat{\sigma}_{a}^{2}$, just like in the BB production economy model. ${ }^{3}$

\section{Potential Resolutions}

This section examines three potential ways to recover BB's main results. Section 5.1 recalibrates the model. Section 5.2 models demand uncertainty with a risk premium shock instead of a preference shock. Section 5.3 draws a connection between disaster risk shocks and preference shocks.

5.1 RECALIBRATION We first checked whether different parameter values would cause a larger decline in output and restore the positive comovement between output, consumption, and investment by rerunning the impulse response matching exercise used by BB. However, the algorithm was unable to find a parameter configuration that closely matched the responses from BB's VAR.

Figure 3 examines why the impulse response matching exercise failed by reproducing the impact effects to the demand uncertainty shock shown in figure $1 \mathrm{~b}$ with different values of the investment adjustment cost parameter $\left(\phi_{k}\right)$, coefficient of relative risk aversion $(\sigma)$, and price adjustment cost parameter $\left(\phi_{p}\right)$. In each case, a larger parameter value attenuates the counterfactual increases in output and investment, especially with a larger IES. If $\phi_{k}$ is sufficiently large, the dynamics in the model approach those in a model with fixed capital, so investment becomes constant and output moves one-for-one with consumption. A higher $\sigma$ makes households more sensitive to changes in volatility. Larger values of $\phi_{p}$ increase the volatility of the price markup and make households more sensitive to the nominal interest rate. Even with implausibly large values for those parameters, investment increases in response to higher uncertainty regardless of the IES. Furthermore, the sizes of the impacts on output are much smaller than BB report, even with parameter values that cause output and investment to decline and address the comovement problem with consumption.

\footnotetext{
${ }^{3}$ The qualitative results are identical when we solve the model with persistent shocks to household preferences.
} 


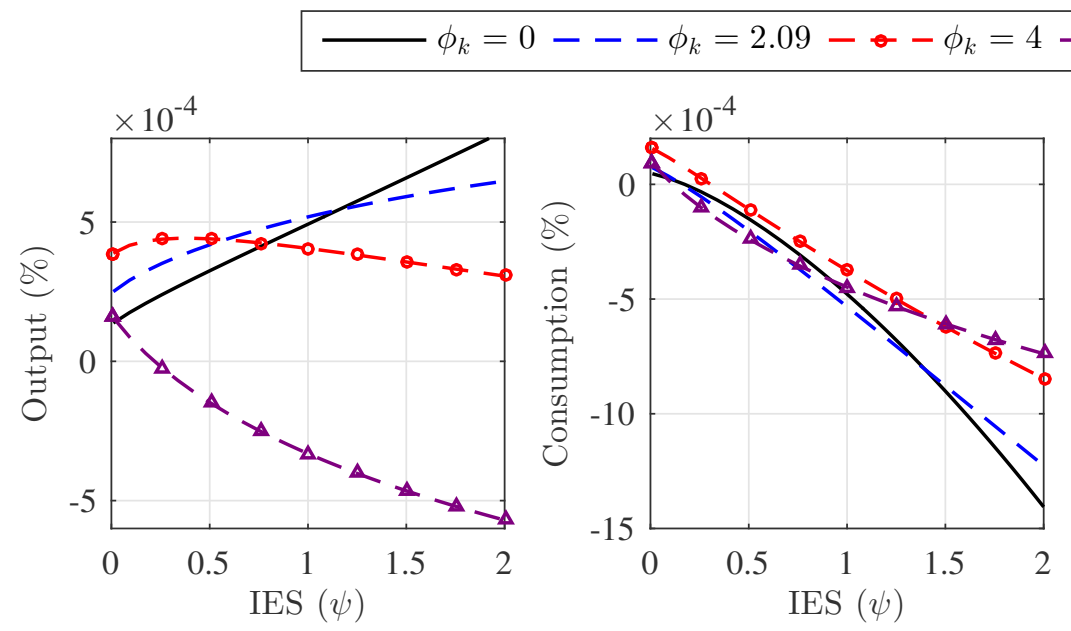

(a) Impact responses as a function of the investment adjustment cost parameter $\left(\phi_{k}\right)$.
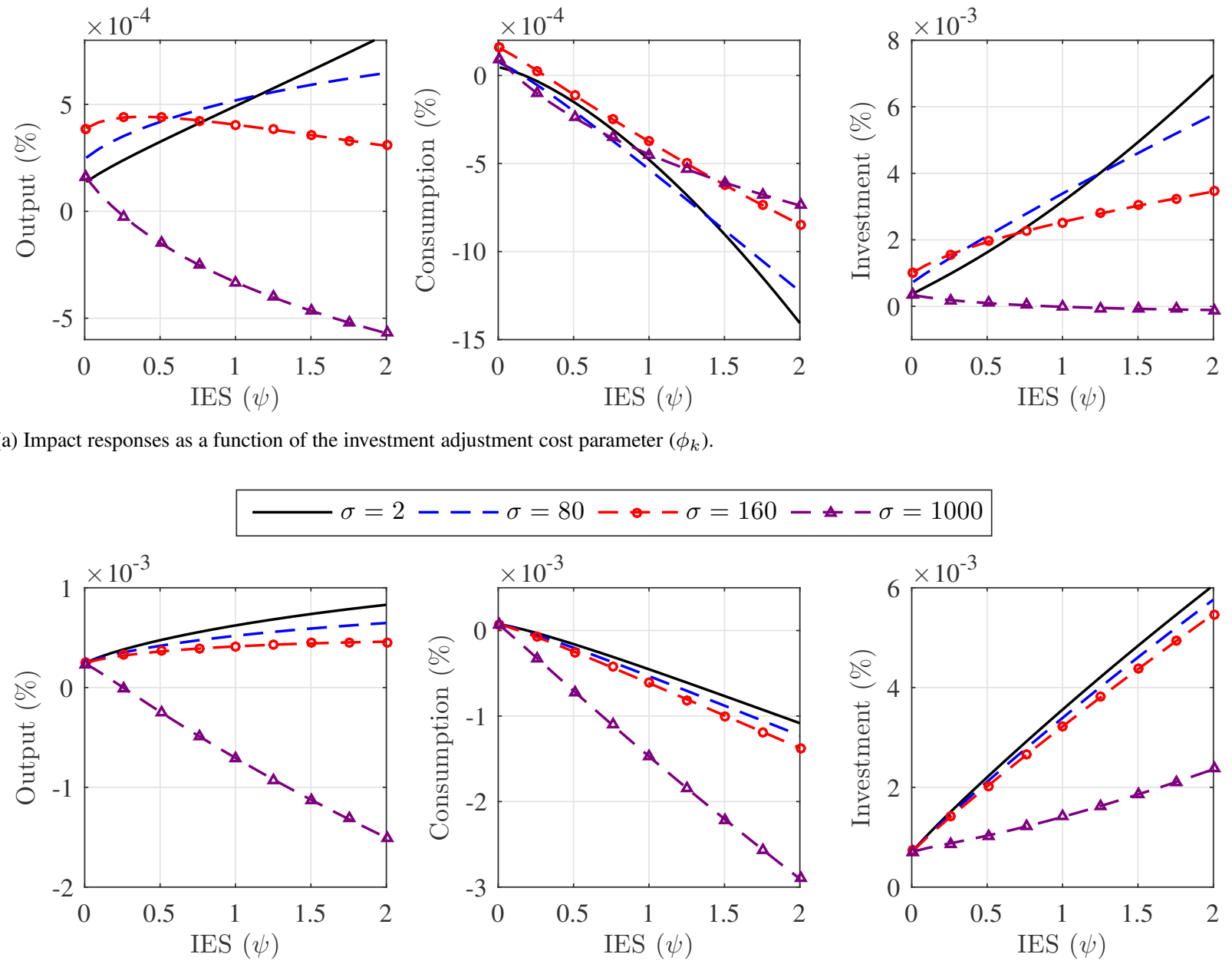

(b) Impact responses as a function of the coefficient of relative risk aversion $(\sigma)$.

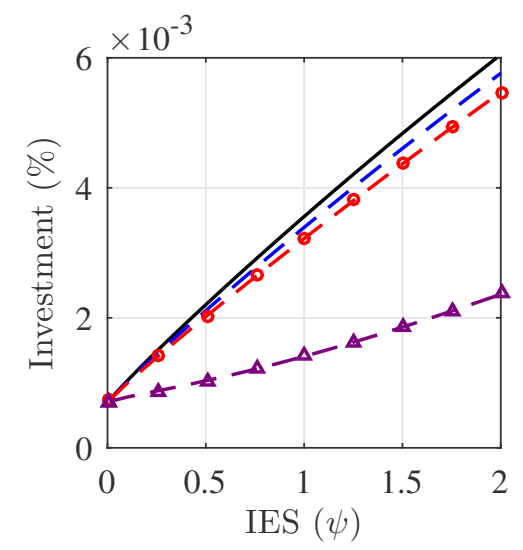

$\longrightarrow \phi_{p}=0---\phi_{p}=100-\bullet-\phi_{p}=200-\star-\phi_{p}=1000$
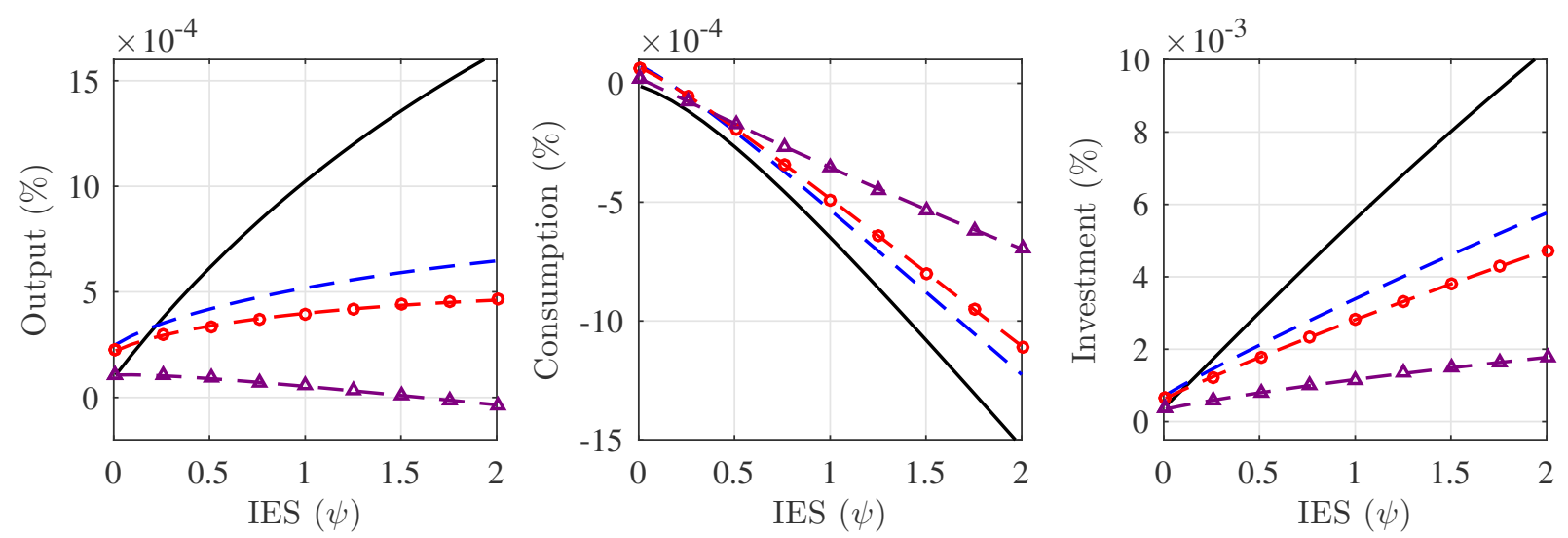

(c) Impact responses as a function of the price adjustment cost parameter $\left(\phi_{p}\right)$.

Figure 3: Impact effect on output, consumption, and investment from a 1 standard deviation volatility shock to the household's preferences. In each panel, the dashed line shows the impact effect with the parameter value from BB. 

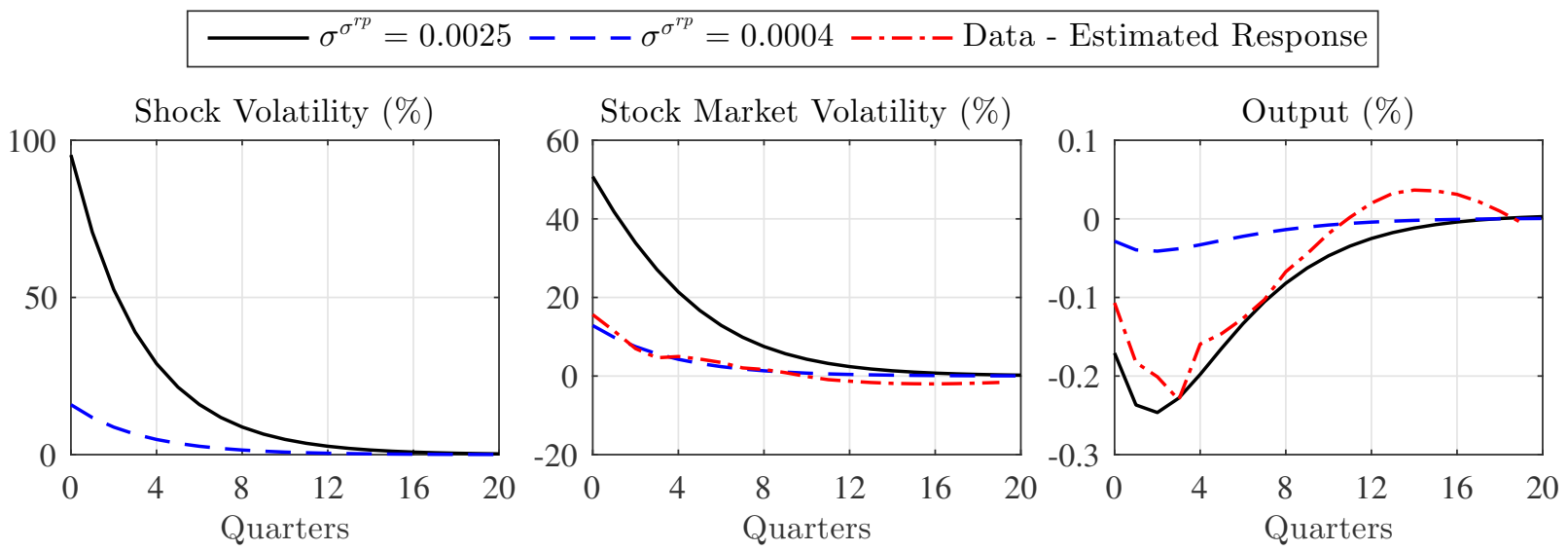

Figure 4: Responses of output and stock market volatility to a 1 standard deviation increase in risk premium volatility.

5.2 Risk PREmiUm Shocks Risk premium shocks are a common alternative to preference shocks because they generate temporary changes in demand. They also help explain the comovement between consumption and investment because risk premium shocks affect the return on riskfree bonds relative to the return on capital. If we set $a_{t}=\bar{a}$ and include a risk premium shock to the return on the nominal bond in the $\mathrm{BB}$ model, then the first-order condition for the bond becomes

$$
1=E_{t}\left[m_{t, t+1} a_{t}^{r p} r_{t} / \pi_{t+1}\right],
$$

where $r_{t}$ is the gross nominal interest rate and $\pi_{t}$ is the gross inflation rate. Following Smets and Wouters (2007), $a_{t}^{r p}$ is a risk-premium shock that follows the same processes given in (2) and (3).

Figure 4 compares the responses of output and stock market volatility from a risk premium volatility shock to the responses from BB's estimated VAR. There is a tradeoff between matching stock market volatility and the response of output. When $\sigma^{\sigma^{r p}}=0.0025$, the model is able to match the response of output from the VAR, but stock market volatility increases 3.25 times more than in the VAR. In contrast, when $\sigma^{\sigma^{r p}}=0.0004$ the model matches the increase in stock market volatility but significantly understates the fall in output. To test the robustness of our result, we reran BB's impulse response matching exercise, replacing the preference shock with a risk premium shock. Once again, the algorithm was unable to find parameters that allow the model to match the VAR.

5.3 DisASTER RISK Gourio (2012) develops a model with time-varying disaster risk, which enters through a combination of permanent and transitory shocks to productivity and a depreciation shock to capital. According to Proposition 3 (p. 2746), if the preference shock in (1) directly hits $u_{t}$, then an increase in the probability of a disaster and a positive shock to household preferences are observationally equivalent. In that case, the recursive structure for intertemporal utility becomes

$$
U_{t}^{B B}=\left[(1-\beta)\left(a_{t}^{d} u\left(c_{t}, n_{t}\right)\right)^{(1-\sigma) / \theta}+\beta\left(E_{t}\left[\left(U_{t+1}^{B B}\right)^{1-\sigma}\right]\right)^{1 / \theta}\right]^{\theta /(1-\sigma)} .
$$

The asymptote no longer appears with unit IES because $a_{t}^{d}$ revalues the current consumptionleisure basket rather than affecting the distributional weights. However, the impact effect of either a level or volatility shock become increasingly large as the IES tends to zero and are near zero for values of the IES above 0.1. While a low IES generates meaningful declines in output from an uncertainty shock to $a_{t}^{d}$, it also creates counterfactually large movements in output from a level 

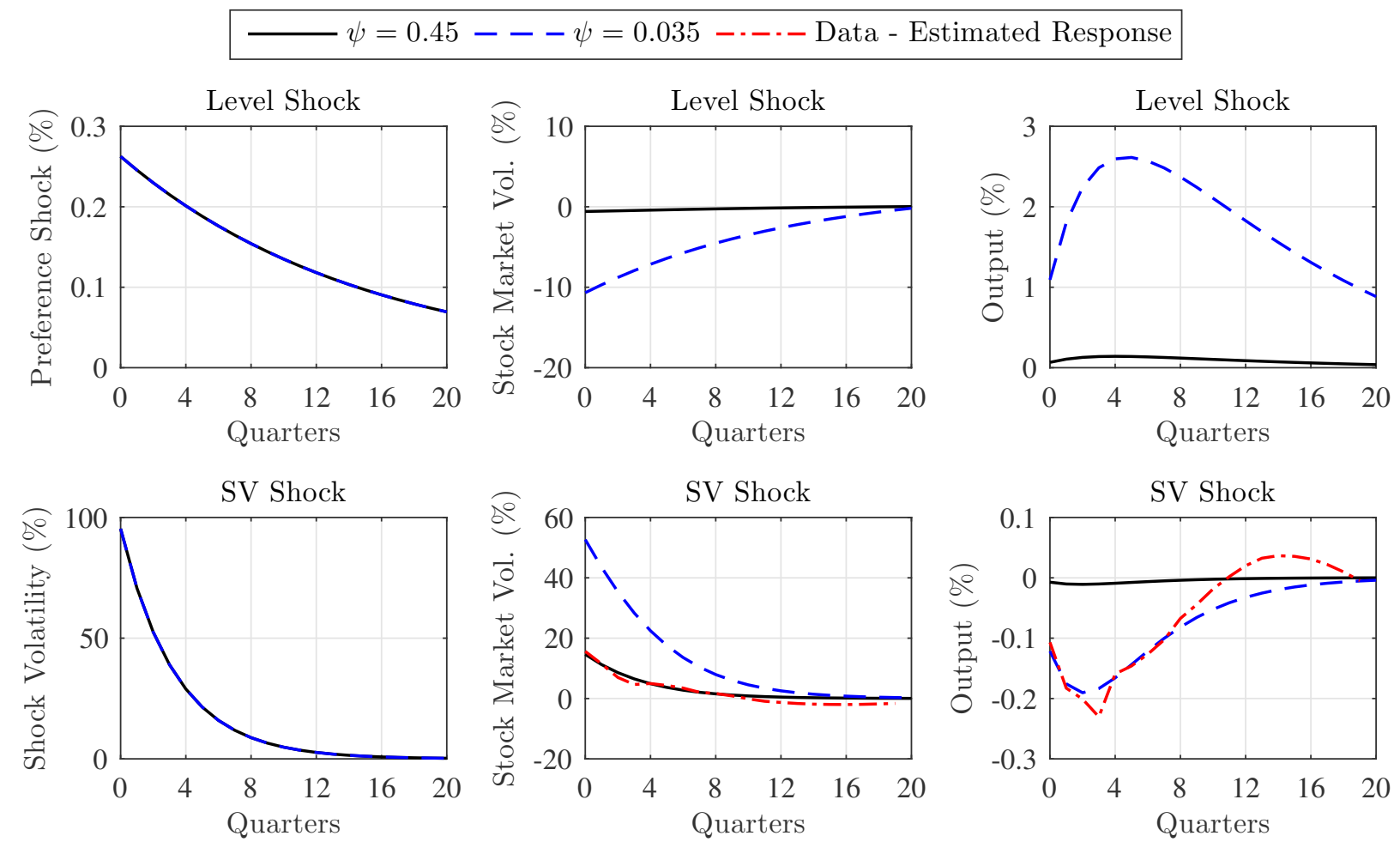

Figure 5: Responses of output and stock market volatility to a 1 standard deviation increase in disaster risk.

shock to $a_{t}^{d}$. There is also a tradeoff between matching the increase in stock market volatility and the decrease in output, just like a risk premium shock. To illustrate, figure 5 plots impulse responses to the "disaster risk" preference shock using two different values for the IES. When $\psi=0.45$, a second moment shock leads to a stock market volatility response that matches the VAR, but first and second moment shocks have little effect on output. When $\psi=0.035$, the decline in output from a second moment shock roughly matches the VAR at the expense of overpredicting stock market volatility. Level shocks also produce counterfactually large responses of both variables. ${ }^{4}$

\section{CONClusion}

BB show flexible price models induce a precautionary labor supply response to higher demand uncertainty that causes output to rise and creates a comovement problem with consumption. Adding sticky prices creates a time-varying markup that $\mathrm{BB}$ contend fixes the problem. Their results, however, stem from using preferences that create an asymptote with unit IES and setting the IES to 0.95 . Our alternative preferences that eliminate the asymptote overturn BB's results by creating small but positive output responses to demand uncertainty shocks and comovement between output, consumption, and investment that is inconsistent with empirical evidence. Even when we change the calibration, replace the preference shock with a risk premium shock, or introduce a disaster risk-type shock, the model is unable to match the data or support BB's main conclusions.

We draw two conclusions. One, consistent with much of the literature, exogenous uncertainty

\footnotetext{
${ }^{4}$ Also, when $\sigma=1 / \psi$ (i.e., expected utility preferences), the SDF becomes $\hat{m}_{t, t+1}=(1-\sigma)\left(\hat{a}_{t+1}^{d}-\hat{a}_{t}^{d}\right)+(1-$ $\sigma)\left(\hat{u}_{t+1}-\hat{u}_{t}\right)+\hat{c}_{t}-\hat{c}_{t+1}$, which is different from the specification of discount rate shocks in the business cycle literature. In particular, with unit IES, the $a_{t}^{d}$ shock drops out of the SDF and has no effect on equilibrium outcomes.
} 
shocks have a rather modest effect on economic activity in this class of models. Two, time-varying markups are insufficient for uncertainty shocks to be a key driver of business cycle fluctuations. That suggests other features are necessary for dynamic stochastic general equilibrium models to explain the role of uncertainty. Identifying those features is an important avenue for future research.

\section{REFERENCES}

Bachmann, R., S. Elstner, And E. Sims (2013): "Uncertainty and Economic Activity: Evidence from Business Survey Data," American Economic Journal: Macroeconomics, 5, 217-49.

BAnsal, R. AND A. YARON (2004): "Risks for the Long Run: A Potential Resolution of Asset Pricing Puzzles," The Journal of Finance, 59, 1481-1509.

BASU, S. AND B. BUNDICK (2017): "Uncertainty Shocks in a Model of Effective Demand," Econometrica, forthcoming.

BASU, S. AND M. KimBALl (2002): "Long-Run Labor Supply and the Elasticity of Intertemporal Substitution for Consumption," University of Michigan Manuscript.

BLOOM, N. (2009): "The Impact of Uncertainty Shocks," Econometrica, 77, 623-685.

Born, B. AND J. PfeIfER (2014): "Policy Risk and the Business Cycle," Journal of Monetary Economics, 68, 68-85.

Epstein, L. G. AND S. E. ZIN (1991): "Substitution, Risk Aversion, and the Temporal Behavior of Consumption and Asset Returns: An Empirical Analysis," Journal of Political Economy, 99, 263-86.

Fernández-Villaverde, J., G. Gordon, P. Guerrón-Quintana, And J. F. RubioRAMÍREZ (2015a): "Nonlinear Adventures at the Zero Lower Bound," Journal of Economic Dynamics and Control, 57, 182-204.

Fernández-Villaverde, J., P. Guerrón-Quintana, K. Kuester, and J. F. RubioRAMÍREZ (2015b): "Fiscal Volatility Shocks and Economic Activity," American Economic Review, 105, 3352-84.

FERnández-Villaverde， J., P. Guerrón-Quintana， J. F. Rubio-Ramírez, And M. URIBE (2011): "Risk Matters: The Real Effects of Volatility Shocks," American Economic Review, 101, 2530-61.

Gourio, F. (2012): "Disaster Risk and Business Cycles," American Economic Review, 102, 2734-2766.

HALL, R. E. (1988): “Intertemporal Substitution in Consumption,” Journal of Political Economy, 96, 339-357.

Justiniano, A. And G. E. Primiceri (2008): “The Time-Varying Volatility of Macroeconomic Fluctuations," American Economic Review, 98, 604-41.

MumtaZ, H. And F. ZANetTi (2013): "The Impact of the Volatility of Monetary Policy Shocks," Journal of Money, Credit and Banking, 45, 535-558.

Richter, A. W. AND N. A. Throckmorton (2017): "A New Way to Quantify the Effect of Uncertainty," FRB Dallas Working Paper 1705.

Rudebusch, G. AND E. SwAnson (2012): "The Bond Premium in a DSGE Model with LongRun Real and Nominal Risks," American Economic Journal: Macroeconomics, 4, 105-43.

SMETS, F. AND R. Wouters (2007): "Shocks and Frictions in US Business Cycles: A Bayesian DSGE Approach," American Economic Review, 97, 586-606.

van Binsbergen, J. H., J. Fernández-Villaverde, R. S. Koijen, And J. RubioRAMÍREZ (2012): "The Term Structure of Interest Rates in a DSGE Model with Recursive Preferences," Journal of Monetary Economics, 59, 634-648. 


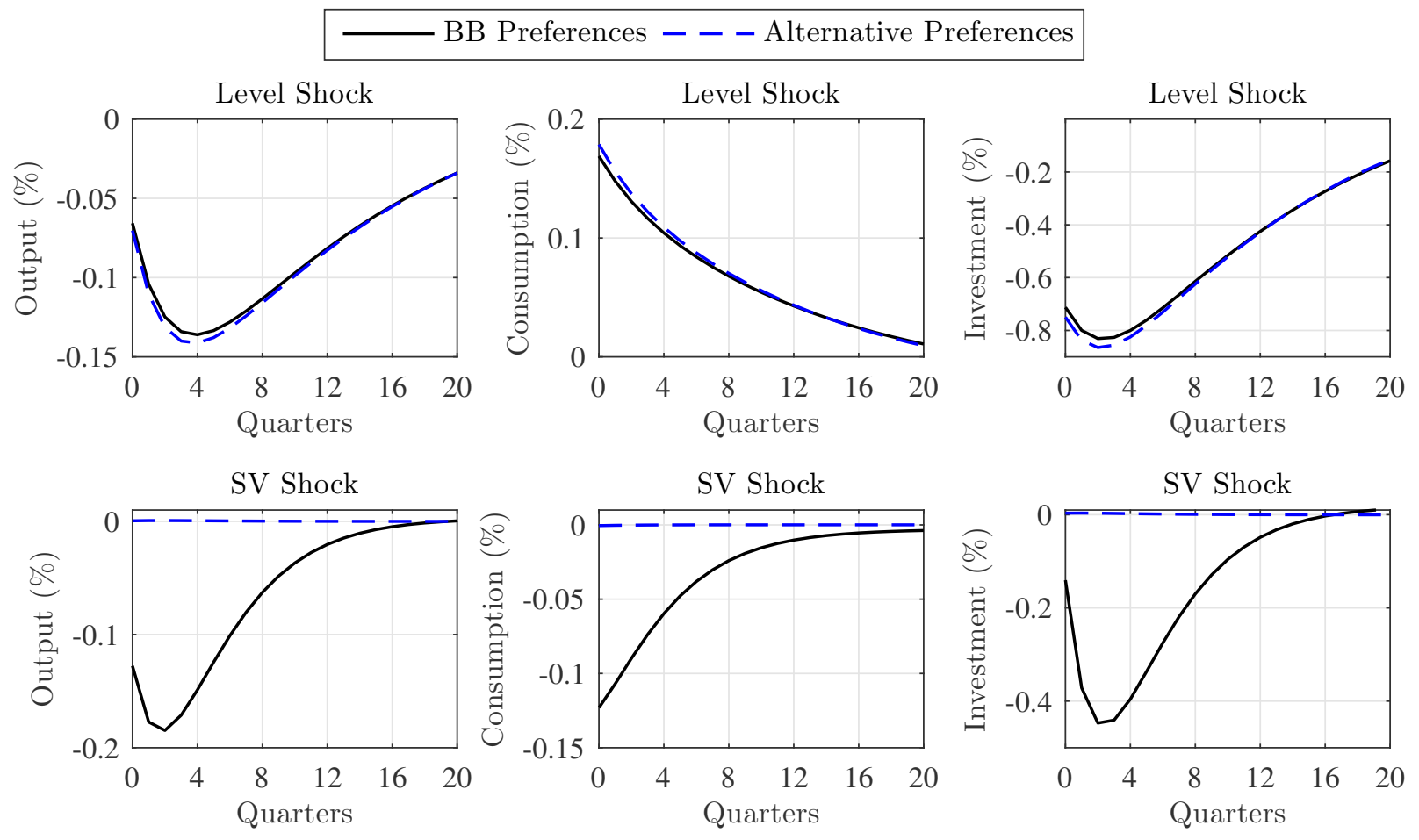

Figure 6: Responses of output, consumption, and investment to a 1 standard deviation preference shock.

\section{A PREFERENCE COMPARISON}

Figure 6 compares impulse responses to a one standard deviation level and volatility shock to household preferences under BB preferences and our alternative specification. All of the parameters, including the IES, are set to the baseline values in BB. The top row shows the responses to the level shock are nearly identical for the two sets of preferences, which validates our transformation of the shock process. The impulse responses to the other shocks in the model-technology level and volatility shocks - are also unaffected by changing the preference specification. The only time the model behaves differently is in response to demand volatility. The bottom row shows the BB preferences produce economically meaningful declines in output, consumption, and investment. In contrast, the economic effects of demand uncertainty shocks under the alternative specification are so small it is difficult to see the shape and size of the responses when plotted on the same axes.

\section{B Impact of Technology Shocks}

This section shows the BB preferences also affect the responses of other shocks. In their appendix, BB introduce a technology volatility shock that evolves in the same way as the preference volatility shock. We set the standard deviation of the volatility shock, $\sigma^{\sigma^{Z}}$, so a one standard deviation shock generates a $95 \%$ increase in volatility, just like the preference volatility shock. The other parameters are set to the values BB estimate in the baseline model, so the responses are directly comparable. Figure 7 reports the impact effect on output from a one standard deviation increase in the level and volatility of technology as a function of the IES. Once again, with the BB preferences an asymptote appears with unit IES, and it goes away when we adjust the weights in the utility function so they sum to one. The results show the effects of the preference shock on the time 

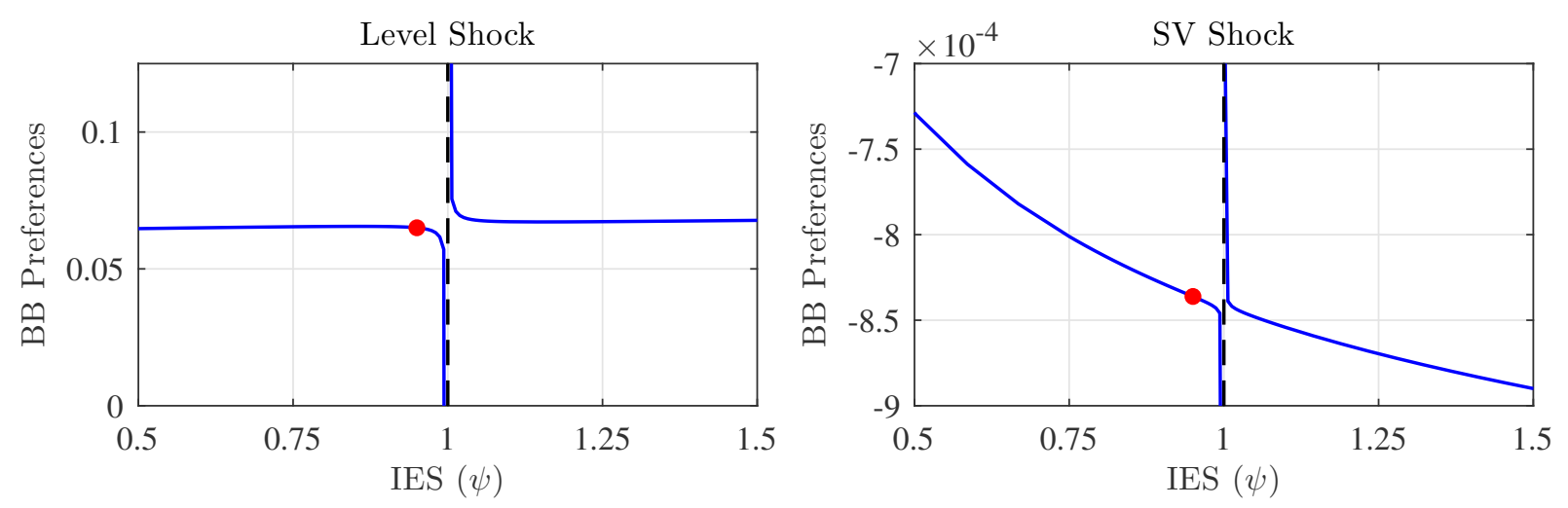

Figure 7: Responses of output to a 1 standard deviation increase in the level and volatility of technology.

aggregator spill over to the predictions of the entire model. Given their calibration, however, the asymptote only has a meaningful effect on the responses when the IES is close to unity. Interestingly, the responses are the same order of magnitude as the responses to the preference volatility shock in figure $1 \mathrm{~b}$. BB show it is possible to increase the response of output by simultaneously increasing $\phi_{k}$ and $\sigma^{Z}$, but in that case the model has trouble matching other features of the data.

\section{Two-PERIOD MOdEL}

The section presents a simple two-period endowment economy with BB preferences that analytically shows the relationship between demand uncertainty and household impatience. We set $\eta=1$ so $u\left(c_{t}, n_{t}\right)=c_{t}$ and $\left\{a_{t+\tau}\right\}_{\tau=0}^{\infty}=\left\{1, a_{t+1}, 0,0, \ldots\right\}$. We assume $\log \left(a_{t+1}\right) \sim \mathbb{N}\left(-\sigma_{a}^{2} / 2, \sigma_{a}^{2}\right)$ so $a_{t+1}>0$ and $E_{t} a_{t+1}=1$, while $a_{t+\tau}$ for $\tau \neq 1$ are known with certainty. Then (1) becomes

$$
U_{t}^{B B}=\left[(1-\beta) c_{t}^{(1-\sigma) / \theta}+\beta\left(E_{t}\left[a_{t+1}^{\theta} c_{t+1}^{1-\sigma}\right]\right)^{1 / \theta}\right]^{\theta /(1-\sigma)} .
$$

The household receives a unit endowment each period and can save, $x_{t}$, at an exogenous net real interest rate $\tilde{r}=0$. For simplicity, we set $\beta=1$ so the optimality condition is given by

$$
\left(1-x_{t}\right)^{-1 / \psi}=\left(E_{t}\left[a_{t+1}^{\theta}\right]\right)^{1 / \theta}\left(1+x_{t}\right)^{-1 / \psi} .
$$

The household's intertemporal choice between consuming today or tomorrow depends on the value of $\mathbb{B} \equiv\left(E_{t}\left[a_{t+1}^{\theta}\right]\right)^{1 / \theta}=E_{t}\left[\exp \left(\theta \log a_{t+1}\right)\right]^{1 / \theta}=\exp \left((\theta-1) \sigma_{a}^{2} / 2\right)$, where $\mathbb{B}$ alters the household's impatience relative to the certainty equivalent case. In the special case when $\sigma_{a}=0, \mathbb{B}=1$ so $x_{t}^{*}=0$ and $c_{t}^{*}=c_{t+1}^{*}=1$. When $\sigma_{a}>0$, we obtain the following conditions (based on $\sigma>1$ ):

1. When $\theta<1$ (i.e., $\psi>1$ or $\psi<1 / \sigma$ ), then $\mathbb{B}<1$ and $c_{t}^{*}>c_{t+1}^{*}$ (impatient households).

2. When $\theta=1$, then $\mathbb{B}=1$ and $c_{t}^{*}=c_{t+1}^{*}$ (certainty equivalent households).

3. When $\theta>1$, just like in BB's calibration, then $\mathbb{B}>1$ and $c_{t}^{*}<c_{t+1}^{*}$ (patient households).

4. As $\theta \rightarrow+\infty\left(\psi \rightarrow 1\right.$ from below), $\mathbb{B} \rightarrow+\infty$ and $c_{t}^{*} \rightarrow 0$.

5. As $\theta \rightarrow-\infty(\psi \rightarrow 1$ from above $)$, then $\mathbb{B} \rightarrow 0$ and $c_{t}^{*} \rightarrow c^{\text {max }}$, where $c^{\text {max }}$ is determined by the natural borrowing constraint. 